\title{
SHOULD WE SCREEN FOR COLORECTAL CANCER?
}

Bernie Towler, Public Health Officer, Epidemiology and Health Services Evaluation Branch;

Les Irwig, A/Professor (Epidemiology), Department of Public Health, University of Sydney;

Marion Haas, Public Health Officer, Epidemiology and Health Services Evaluation Branch;

Angela Plunkett, Associate Lecturer, Department of Public Health, University of Sydney;

Glenn Salkeld, Lecturer (Health Economics), Department of Public Health, University of Sydney.

\section{INTRODUCTION}

n NSW in 1991 colorectal cancer was the second most common cancer affecting women and men, after breast and prostate cancer, respectively'. Because of the burden of this disease and because prevention is not possible, populationbased screening to detect and remove colorectal adenomas and early asymptomatic cancers has been advocated by some ${ }^{2}$. However, the decision to implement population-based screening is a complex one. Early detection and treatment of colorectal neoplasms (adenomas and cancers) must be shown to be effective in reducing disease mortality and any benefits of screening must outweigh potential morbidity caused. Other considerations include the feasibility, cost and acceptability of screening to Australians and the likelihood of patient and physician compliance with a screening program.

We examined the evidence about the effectiveness of screening and related issues to inform screening policy. This included a comprehensive and critical review of the literature, preliminary economic analysis of screening in the Australian health care setting and correspondence with Australian investigators for information about local research relevant to screening. A summary of this review and its recommendations are presented below and in Table 4. The full report, including the tabulated results of the critical appraisal of the literature, is available from the Epidemiology and Health Services Evaluation Branch.

\section{IS SCREENING EFFECTIVE?}

Whether screening is effective is the first and crucial question to ask before embarking on a screening program. Randomised controlled trials provide the best quality evidence about screening effectiveness. There are five large trials (one non-randomised) investigating the effectiveness of screening using the faecal occult blood test (FOBT) Hemoccult ${ }^{34,5,5,7,7,9,10,11,12,13}$. The New York trial ${ }^{12,13}$ is evaluating Hemoccult additional to sigmoidoscopy which was offered to all study participants. The major characteristics and mortality findings of the trials are given in Table 5 . In all trials, Hemoccult positive subjects were referred for further investigation which was mainly colonoscopy, or alternatively, sigmoidoscopy with double contrast barium enema. Colorectal neoplasms detected were removed.

Three of the trials have reported mortality findings, analysed by intention to treat ${ }^{4,11,13}$. Only the Minnesota trial ${ }^{4}$ has reported a statistically significant 33 per cent reduction in colorectal cancer mortality with annual screening (Table 5). However, the findings of the Minnesota trial must be viewed with caution for several reasons. There are inconsistencies in the numbers of colorectal cancers

\section{Hospital-related mortality in NSW}

\section{$\checkmark$ Continued from page 26}

While our development of risk-adjusted indicators is still at an early stage, there are a few excellent examples of clinical groups in NSW that have produced and implemented such indicators to monitor the quality of their services. One such example is the Australian and New Zealand Intensive Care Society (ANZICS). ANZICS, partially funded by the NSW Health Department's Health Outcomes Program, is installing a standard clinical information system in intensive care units throughout Australia to provide riskadjusted mortality data to the participating units. The information from this system will allow individual units to compare their overall performance and condition-specific mortality to an international benchmark and facilitate monitoring of trends in performance. The development of such systems is complementary to the work being carried out in the Epidemiology and Health Services Evaluation Branch.

The next steps in our exploration of hospital mortality will be to:

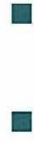

recalculate in-hospital mortality rates adjusting for age, sex and casemix, and condition-specific mortality rates adjusting for age and sex; evaluate methods for using existing inpatient data in the measurement of co-morbidity and severity of illness and in risk adjustment; compare the use of routinely reported inpatient data and these algorithms against results derived from more comprehensive clinical databases, e.g. Trauma Registries;

demonstrate the feasibility and usefulness of linking routinely reported inpatient data to mortality data to extend this analysis to include post-discharge deaths; and

assess the usefulness of additional data items from existing hospital information systems and processes which may be of value in the measurement of comorbidity, severity of illness and risk adjustment. This evaluation will determine whether suitable data items are captured by hospital records, the extent and consistency of recording across institutions and the feasibility of computerisation.

This work will be assisted by a grant from the Commonwealth Government and will include collaboration with the Victorian Department of Health and Community Services.

1. US Congress, Office of Technology Assessment. The Quality of Medical Care: Information for Consumers, OTA-H-386 (Washington, DC. US Government Printing Office, June 1988) Chapter 4 p71. 2. International Classification of Diseases and Causes of Death, 9 th Revision, Clincial Modification Vol 1, 1986. Ann Arbor Michigan Library of Congress No. 77-94472.

3. NSW Public Hospital Comparison Data 1991/2. NSW Health Department, State Health Publication No. (IC) 93-134.

4. Elixhauser A, Andrews RM, and Fox S. Clinical Classification for Health Policy Research: Discharge Statistics by Principal Diagnosis and Procedure. Division of Provider Studies Research Note 17 Agency for Health Care Policy and Research, 1993 Rockville, MD Public Health Service (ACHCPR Publication No. 93-0043) 


\section{TABLE 4}

SUMMARY OF REVIEW AND RECOMMENDATIONS ABOUT COLORECTAL CANCER SCREENING

1. Population screening is not recommended as screening effectiveness has not yet been adequately established.

Follow-up continues in the major trials and review of this

position will be necessary in a few years time when further information is available.

2. Although evidence for screening persons at high risk, such as those with a known genetic susceptibility for colorectal cancer, is also lacking, it seems prudent to screen such groups on the basis of the increased risk.

3. Further work is needed in Australia to determine the implications of introducing screening for health services planning and costs, to determine the most accurate and feasible screening test and the likely compliance of Australians with screening, and to determine and cater for the psychosocial consequences of screening.

reported, information about vital status for all study participants at follow-up is not given, there is no intermediate biennial screening benefit and about one-third of all people screened had colonoscopy with its attendant risks and costs. It is possible that using colonoscopy alone on a random sample of one-third of people from either group would have resulted in this mortality reduction.

The New York trial ${ }^{13}$ has reported a borderline significant 43 per cent reduction in colorectal cancer mortality with annual screening in one of the subgroups examined (Table 5). But the New York trial was a non-randomised study and study groups were demonstrably not comparable, suggesting bias in the allocation of subjects to study groups. The Danish trial ${ }^{11}$ has reported a non-significant 17 per cent reduction in colorectal cancer mortality with biennial screening (Table 5). Follow-up continues in four of the five trials. In the interim, evidence for the effectiveness of screening using Hemoccult remains inconclusive.

Screening using flexible sigmoidoscopy has been suggested ${ }^{2}$. The only evidence about screening effectiveness using sigmoidoscopy comes from two recent case-control studies $^{14,15}$. The authors reported $60-80$ per cent reductions in colorectal cancer mortality with sigmoidoscopic screening but these results must be interpreted cautiously because of the biases inherent in case-control studies to evaluate screening. In addition, sigmoidoscopy is more invasive and expensive than Hemoccult and has an estimated rate of bowel perforation of 0.02 per cent ${ }^{16}$. Randomised trials evaluating the effectiveness of screening using sigmoidoscopy are under way in the United Kingdom ${ }^{17}$ and the United States ${ }^{18}$. There are no studies investigating the effectiveness of screening using colonoscopy. However, colonoscopy is probably unsuitable as a screening test as it is expensive, invasive, requires sedation and bowel preparation and has an estimated complication rate of perforation, haemorrhage and death of 0.17 per cent, 0.03 per cent and 0.02 per cent respectively.

\section{FAECAL OCCULT BLOOD TESTS (FOBTS)}

The major trials are evaluating screening using Hemoccult, an inexpensive guaiac-based FOBT which detects blood products in faeces. Estimates of the sensitivity of Hemoccult for detecting colorectal cancer in asymptomatic populations vary greatly (22-92 per cent $\left.{ }^{3,5-9,20}\right)$. More recent immunochemical FOBTs appear to have greater sensitivity than Hemoccult without loss of specificity ${ }^{21,22}$, but the newer tests need further evaluation in asymptomatic populations. The value of detection of colorectal adenomas with FOBTs in reducing mortality from colorectal cancer remains unclear although researchers from the Minnesota trial ${ }^{4}$ suggest this may become clearer with further follow-up.

GROUPS AT INCREASED RISK OF COLORECTAL CANCER

People with a known genetic predisposition for colorectal cancer such as those with familial adenomatous polyposis or hereditary non-polyposis colorectal cancer (HNPCC) have a markedly increased risk of colorectal cancer: 50 per cent of the children of people affected with HNPCC are reported to develop colorectal cancer ${ }^{23}$. Thus, despite uncertainty about the trial evidence, screening seems prudent for these people in the light of their high risk. People with a family history of colorectal cancer with no known genetic basis have a two- to four-fold increased risk of colorectal cancer ${ }^{23}$. The decision to screen or not screen such people is less clear and should be left to the individuals and their medical practitioners.

\section{WOULD AUSTRALIANS PARTICIPATE IN SCREENING?}

Assuming that colorectal cancer screening is effective, compliance of the Australian population with screening would be critical to the ability of a screening program to reduce mortality rates. The notion of compliance is complex, encompassing initial and continued participation in screening and adherence to follow-up, treatment recommendations and post-treatment surveillance.

Compliance of screen-positive people with follow-up investigations is essential to maximise the effectiveness of screening. Compliance with follow-up was high in the major trials (77-93 per cent). However, the numbers of eligible people who choose to participate in screening will influence the public health impact of the screening program in its ability to reduce colorectal cancer mortality. Compliance with initial Hemoccult testing ranged from 53 per cent to 80 per cent in the major trials (Table 5 ) and was positively associated with younger age and female gender. Compliance with rescreening, where offered to all those in the screen group, not just previous compliers, was lower (20-58 per cent, Table 5). Personalised invitations to screening, reminder letters or telephone calls increased compliance in the trials and other studies ${ }^{24.25}$. Preliminary Australian research on compliance with colorectal cancer screening has been done $e^{26.27 .28}$ but more work is needed to assess barriers to screening participation and to test strategies for overcoming these barriers.

\section{PSYCHOSOCIAL IMPACT OF SCREENING}

In the major trials, screening with Hemoccult resulted in a positive predictive value for cancer ranging from 2 per cent to 18 per cent and 2 to 4 per cent if Hemoccult slides were rehydrated (Table 5). Therefore, more than 80 per cent of positives are false positives: such large numbers of people receiving falsely positive results is important since a positive result is not unexpectedly associated with distress ${ }^{24,29}$. All these people would require colonoscopy, an invasive procedure which, in addition to the physical risk, may cause pain and embarrassment ${ }^{30}$ and significant anxiety $y^{31}$. There is also evidence from other screening programs that anxiety aroused by a false positive result 


\section{TABLE 5}

SUMMARY OF CHARACTERISTICS AND MORTALITY RESULTS OF TRIALS OF HEMOCCULT SCREENING FOR COLORECTAL CANCER

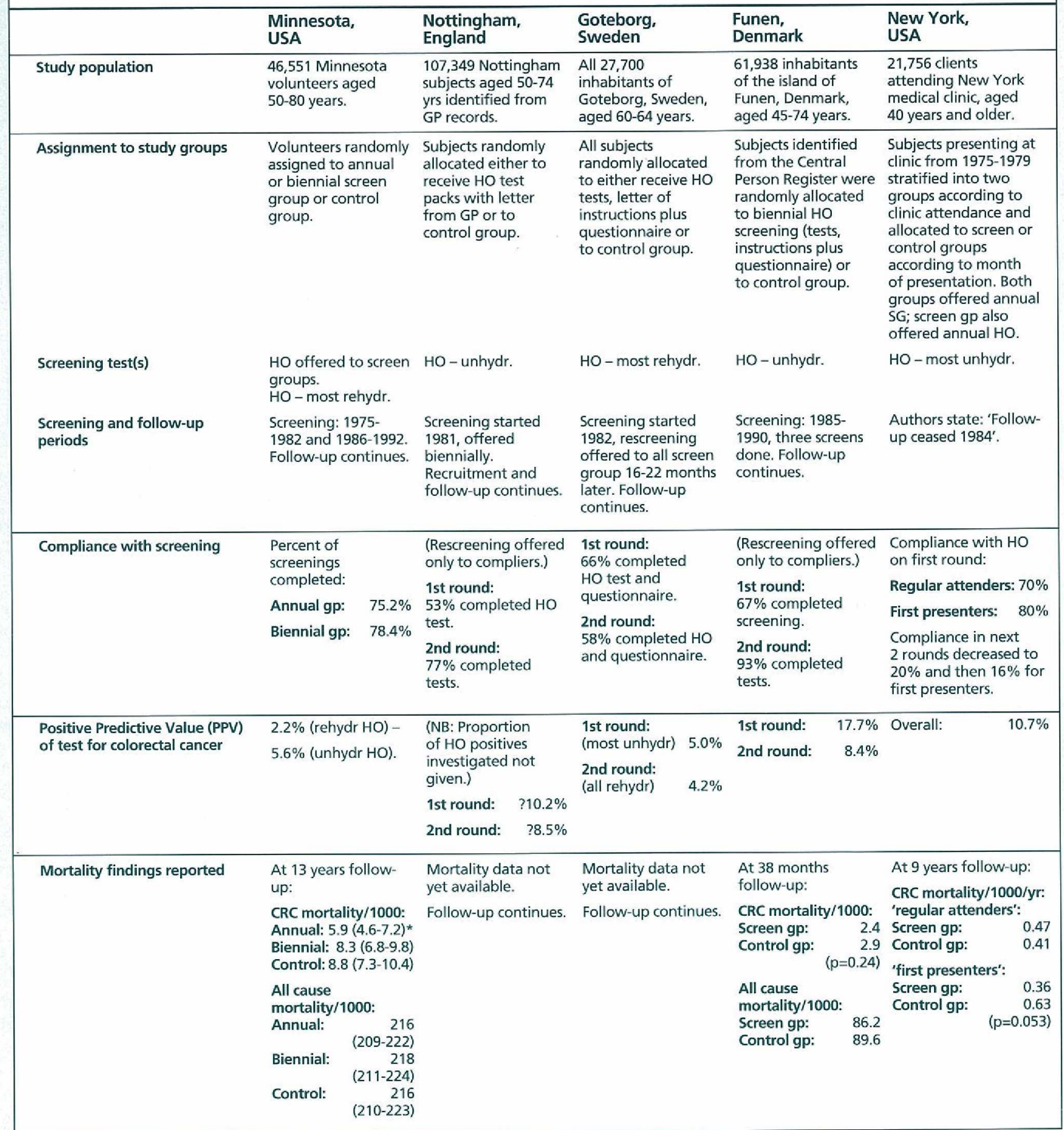

HO - Hemoccult II; CRC - Colorectal Cancer; SG - Sigmoidoscopy; rehydr - Rehydrated; unhydr - Unhydrated. *95\% Confidence Intervals in brackets. 


\section{Colorectal cancer}

\section{Continued from page 29}

may be long term ${ }^{32}$ and negative results may reassure people who then do not seek medical care for rectal bleeding ${ }^{29}$. Implementation of screening requires attention to the provision of appropriate information about its purpose and pitfalls. There also need to be support services for people receiving, and undergoing investigation for, positive test results.

\section{ECONOMIC CONSIDERATIONS}

The risks, benefits and costs are major factors in decisions about screening. Information on screening benefits in terms of survival with and without the disease remains unclear without conclusive randomised trial evidence but assumptions about survival, the natural history of the disease, the screening procedures and clinical history can be made to compare the costs and benefits of screening. In the US, Eddy ${ }^{33}$ has evaluated three screening strategies which resemble proposed Australian screening guidelines ${ }^{2,23}$ : annual FOBT, annual FOBT plus sigmoidoscopy every five years and annual FOBT plus colonoscopy every five years. The estimated cost-effectiveness ratio for each strategy was $\$ U S 8,800, \$ U S 7,760$ and $\$$ US20,700 per life year gained respectively. However, based on the findings of the Minnesota trial, the cost-effectiveness of FOBT screening may be considerably underestimated ${ }^{34}$. We have begun preliminary estimates of the cost-effectiveness of screening in an Australian context using Australian cancer incidence data and Australian health care costs. The results of this analysis will be reported when available.

\section{CONCLUSION AND RECOMMENDATIONS}

Contrary to the recommendations of The Gut Foundation ${ }^{2}$, we recommend that screening for colorectal cancer should not be implemented on a population basis as there is not sufficient evidence of its effectiveness. This position will need review when further trial evidence becomes available. Screening for groups at high risk of colorectal cancer such as those with a known genetic predisposition seems prudent on the basis of the increased risk. If evidence accruing from the trials over the next few years warrants a decision to screen, it must be with the support of general practitioners, with quality control for FOBTs and with adequate linkage to ensure appropriate management and follow-up of people with positive results ${ }^{23}$. In addition, there must be monitoring and evaluation of the screening program's ability to detect early cancers and minimise the interval cancer rate. In the interim, further investigation in the areas of compliance, psychosocial impact and better screening tests, as well as more detailed economic evaluation, is needed.

1. Coates M, McCredie M, Taylor R. Cancer in New South Wales. Incidence and Mortality 1991. Sydney: NSW Central Cancer Registry, 1994.

2. The Gut Foundation Working Party. Colorectal Cancer: Prevention, Diagnosis, Treatment. Randwick: The Gut Foundation Research Institute, 1993

3. Mandel JS, Bond JH, Bradley M, Snover DC, Church TR, Williams S et al. Sensitivity, Specificity, and Positive Predictivity of the Hemoccult Test in Screening for Colorectal Cancers. Gastroenterology 1989; 97(3):597-600.

4. Mandel JS, Bond JH, Church TR, Snover DC, Bradley GM, Schuman LM, Ederer F. Reducing mortality from colorectal cancer by screening for fecal occult blood. $N$ Engl J Med 1993; 328(19):1365-71.
5. Hardcastle JD, Chir M, Armitage NC, Chamberlain J, Amar SS, James PD, Balfour TW. Fecal Occult Blood Screening for Colorectal Cancer in the General Population. Results of a Controlled Trial. Cancer 1986; 58(2):397-403.

6. Hardcastle JD, Chamberlain J, Sheffield J, Balfour TW, Armitage NC, Thomas WM et al. Randomised, Controlled Trial of Faecal Occult Blood Screening for Colorectal Cancer. Results for the First 107,349 Subjects. The Lancet 1989; May 27:1160-4.

7. Kewenter J, Bjork S, Haglind E, Smith L, Svanvik J, Ahren C. Screening and Rescreening for Colorectal Cancer. A Controlled Trial of Fecal Occult Blood Testing in 27,700 Subjects. Cancer 1988; 62(3):645-51. 8. Kronborg O, Fenger C, Olsen J, Bech K, Sondergaard O. Repeated 8. Kronborg O, Fenger C, Olsen J, Bech K, Sondergaard O. Repe
Screening for Colorectal Cancer with Fecal Occult Blood Test. A Prospective Randomized Study at Funen, Denmark. Scand $J$ Gastroenterol 1989; 24:599-606.

9. Klaaborg K; Madsen MS, Sondergaard O, Kronborg O. Participation in Mass Screening for Colorectal Cancer with Fecal Occult Blood Test. Scand J Gastroenterol 1986; 21:1180-4.

10. Kronborg A, Fenger C, Sondergaard O, Pedersen KM, Olsen J. Initial Mass Screening for Colorectal Cancer with Fecal Occult Blood Test. Scand J Gastroenterol 1987; 22:677-86.

11. Kronborg O, Fenger C, Worm J, Pedersen SA, Hem J, Bertelsen K Olsen J. Causes of Death during the First 5 Years of a Randomized Trial of Mass Screening for Colorectal Cancer with Fecal Oecult Blood Test. Scand J Gastroenterol 1992; 27:47-52.

12. Flehinger BJ, Herbert E, Winawer SJ, Miller DG. Screening for colorectal cancer with fecal occult blood test and sigmoidoscopy: Preliminary Report of the Colon Project of Memorial Sloan-Kettering Cancer Center and PMT-Strang Clinic. In Chamberlain J, Miller AB, eds. Screening for Gastrointestinal Cancer (International Union Against Cancer). Toronto: Hans Huber, 1988; 9-16.

13. Winawer SJ, Flehinger BJ, Schottenfeld D, Miller DG. Screening for Colorectal Cancer With Fecal Occult Blood Testing and Sigmoidoscopy. J Nat Cancer Inst 1993; 85(16):1311-8.

J Nat Cancer Inst 1993; 85(16):1311-8.
14. Selby JV, Friedman G, Quesenberry CP, Weiss NS. A Case-Control 14. Selby JV, Friedman G, Quesenberry CP, Weiss NS. A Case-Control
Study of Screening Sigmoidoscopy and Mortality from Colorectal Cancer. N Engl J Med 1992; 326:653-7.

15. Newcomb PA, Norfleet RG, Storer BE, Surawicz TS, Marcus PM Screening Sigmoidoscopy and Colorectal Cancer Mortality. J Nat Cancer Inst $1992 ; 84(20): 1752-5$.

16. Diagnostic and Therapeutic Technology Assessment (DATTA). Rigid and Flexible Sigmoidoscopies. JAMA 1990; 264(1):89-92.

17. Robinson MHE, Berry DP, Vellacott KD, Moshakis V, Hardcastle JD. A Randomised Trial of Flexible Sigmoidoscopy and Haemoccult Vs Haemoccult Alone in Colorectal Cancer Population Screening. Gut 1993 34(1):S40.

18. Kramer B, Gohagan J, Prorok PC, Smart C. A National Cancer
I4t Institute Sponsored Screening Trial for Prostatic, Lung, Colorectal, and Ovarian Cancers. Cancer 1993; 71:589-93.

19. Habr-Gama A, Waye JD. Complications and Hazards of Gastrointestinal Endoscopy. World J Surg 1989; 13(2):193-201. 20. Allison JE, Feldman R, Tekawa IS. Hemoccult Screening in Detecting Colorectal Neoplasms: Sensitivity, Specificity, and Predictive Value. Ann Intern Med 1991; 112(5):328-33.

21. St John DJB, Young GP, Alexeyeff MA, Deacon MC, Cuthbertson AM, Macrae FA, Penfold JCB. Evaluation of New Occult Blood Tests for Detection of Colorectal Neoplasia. Gastroenterology 1993; 104(6):1661-8. 22. Thomas DW. Colon cancer detection based on the radial immunodiffusion test, 'Detectacol'. In: Young GP, Saito H, eds. Faecal Occult Blood Tests. San Jose: SmithKline Diagnostics Inc, 1992; 76-81. 23. Australian Gastroenterology Institute and the Australian Cancer Society. Guidelines for Early Detection and Prevention of Colorectal Cancer. Sydney, 1994. In press.

24. Arveux P, Durand G, Milan C, Bedenne L, Levy D, Bui DHD, Faivre $J$. Views of a general population on mass screening for colorectal cancer: the Burgandy study. Prev Med 1992:21:574-81.

25. Mant D, Fuller A, Northover J, Astrop P, Chivers A, Crockett A, et al Patient compliance with colorectal cancer screening in general practice. Brit J Gen Pract 1992; 42:18-20.

26. Fairbrother G, King J, Morris DC. The effect of a local community media educational campaign on compliance with faecal occult blood screening. Health Prom J Aust. In press.

27. King J, Fairbrother G, Thompson C, Morris DC. The influence of socio-economic status, ethnicity and an educational brochure on compliance with faecal occult blood testing in Australia. Aust J Public Health. In press.

28. Weller DP, Hiller JE, Willson K, Wilson D, Owen N, Colorectal cancer and its prevention: knowledge, attitudes and beliefs in the South Australian Population. Unpublished

29. Mant D, Fitzpatrick R, Hogg A, Fuller A, Farmer A, Verne J Northover J. Experiences of patients with false positive results from colorectal cancer screening. Brit J Gen Pract 1990; 40:423-5. 30. McCarthy BD, Moskowitz MA. Screening flexible sigmoidoscopy: patient attitudes and compliance. J Gen Intern Med 1993; 8:120-5. 31. Fox E, O'Boyle C, Lennon J, Keeling PWN. Trait anxiety and coping style as predictors of pre-operative anxiety. Brit J Psychol 1989; 28:89-90. 32. Turnbull D, Irwig L, Simpson J. Long-term psychological morbidity after false positive screening mammograms. Unpublished. 33. Eddy DM. Screening for colorectal cancer. Annals of Internal Medicine 1990; 113:373-84.

34. Brown ML. Screening for colorectal cancer [letter]. N Engl J Med 34. Brown ML. Screen
1993; 329(18): $1352-3$. 